\title{
PRÁTICAS ILÍCITAS E SEUS ATORES: UM ESTUDO SOBRE REPRESENTAÇÕES SOCIAIS
}

\author{
Anna Beatriz Carnielli Howat-Rodrigues
}

Universidade de São Paulo, São Paulo, SP, Brasil.

Danielly Bart do Nascimento

Universidade Federal do Espírito Santo, Vitória, ES, Brasil.

Edinete Maria Rosa

Universidade Federal do Espírito Santo, Vitória, ES, Brasil.

Júlio César Pompeu

Universidade Federal do Espírito Santo, Vitória, ES, Brasil.

\begin{abstract}
Resumo
O objetivo do presente artigo foi compreender a representação social de adultos autores de atos infracionais, importante para o levantamento de expectativas sociais construídas nas relações cotidianas. Participaram deste estudo 55 estudantes universitários dos cursos de Direito e Psicologia. Os instrumentos constituíram de questionário sociodemográfico sobre características dos participantes e questionário estruturado de ativação contextual com manipulação de variável econômica bairro (rico X pobre). Utilizou-se teste Qui-quadrado ou o Teste de Fischer a fim de examinar associações entre as variáveis. No geral, os estudantes atribuíram àquele que infringe a lei, cor/etnia parda, sem união estável e sem trabalho, justificando a aceitação de praticar atos ilícitos a partir de fatores socioeconômicos e prevendo a prisão ou a pena prevista em lei como forma de punir. As representações sociais mostram-se perpassadas pelo discurso das classes dominantes pautado numa visão punitiva e vingativa contrário ao discurso de reeducação e inserção social difundida em ambos os círculos acadêmicos.
\end{abstract}

Palavras-chave: questões sociais, influências sociais, estigma.

\section{MALPRACTICE AND ITS ACTORS: A STUDY ON SOCIAL REPRESENTATIONS THEORY}

\begin{abstract}
The paper aimed to understand the social representation of adult offending, important for the survey of social expectations built in everyday relationships. The subjects were 55 university law and psychology students. The instruments consisted of a questionnaire on sociodemographic characteristics of participants and a structured questionnaire for contextual activation with manipulation of economic variable through the neighborhood (rich $x$ poor). Chi-square or Fischer test were used to examine associations between variables. In general, students indicated that the person involved in the crime were mulatto ethnicity, without work and without marital stability. The students justified the acceptance of practicing unlawful acts from socioeconomic factors and believed the arrest or the punishment prescribed by law as a way of punishment those who break the law. Social representations appeared to be based by the discourse of the dominant classes guided by a punitive and vindictive speech, vision opposed to rehabilitation and social integration widespread in both academic circles.
\end{abstract}

Key-words: social issues, social influences, stigma. 


\title{
ILÍCITO DE PRÁTICAS Y SUS AGENTES: UN STUDIO SOBRE LAS REPRESENTACIONES SOCIALES
}

\begin{abstract}
Resumen
El objetivo del presente artículo fue el de comprender las representaciones sociales existentes sobre adultos autores de delitos, importantes para el análisis de expectativas sociales construidas en las relaciones cotidianas. Los participantes de este estudio fueron 55 estudiantes universitarios provenientes de las carreras de Derecho y Psicología. Los instrumentos aplicados fueron, en primer lugar, un cuestionario de características sociodemográficas $y$, después, un cuestionario estructurado de activación contextual donde se manipuló la variable económica "barrio" (ricos vs pobres). Para examinar las asociaciones entre variables se usó Chi-cuadrado y el Test Exacto de Fisher. En general, los estudiantes atribuyeron al delincuente raza/etnia negra, sin unión estable y desempleado, justificando la tendencia a cometer actos ilícitos en base a factores socioeconómicos, y anticipando la prisión o la sanción prevista por la ley como forma de castigo. Las representaciones sociales parecen estar impregnadas por el discurso de las clases dominantes, marcadas por una visión punitiva y vengativa, un punto de vista opuesto al de la rehabilitación y la reinserción social que se difunde en círculos académicos.
\end{abstract}

Palabras clave: temas sociales, influencias sociales, estigma.

\section{INTRODUÇÃO}

A maneira como o homem se insere no mundo, suas características pessoais, sociais, entre outras, permitem-no formular explicações diversas sobre objetos oriundos das práticas cotidianas. A construção do conhecimento pelos grupos sociais organiza o significado de diferentes estímulos do meio e conduz a relação do grupo com o mundo e com os outros. Este sistema de interpretação pode ser nomeado de Representação Social. O termo, cunhado por Moscovici em 1972 diz respeito ao entendimento dos significados adquiridos pelos objetos sociais compreendendo-os como explicações e prescrições da realidade social (Alexandre, 2004; Brito \& Catrib, 2005).

As representações sociais podem ter função de: 1) compreender e explicar a realidade, permitindo com que os atores sociais desenvolvam conhecimentos que irão se integrar aos seus valores e cognições; 2) definir a identidade e auxiliar na proteção das características grupais, garantindo uma imagem positiva do mesmo; 3) direcionar comportamentos e práticas; e 4) justificar as decisões sobre posições assumidas e comportamentos externalizados (Abric, 1998).

O cunho que a representação pode assumir, entretanto, pode ser arraigado de pré-julgamentos superficiais sobre uma realidade que norteiam um determinado grupo comportamentalmente e cognitivamente. Bellodi (2004), apoiado em Moscovici, identifica que a simplificação da realidade serve ao grupo social para que ele interprete as informações complexas que sua percepção tem 
dos outros indivíduos e grupos que Ihe são desconhecidos, construindo, assim, estereótipos.

Apesar de não ser um dos países mais pobres do mundo, o Brasil caracteriza-se por apresentar uma grande desigualdade na distribuição de renda, na acessibilidade aos bens de consumo, aos bens culturais e na oferta insuficiente e em alguns casos inadequada de políticas públicas. Além disso, é comum o preconceito racial com desvalorização de traços de descendência africana (Queiroz \& Otta, 2000). Soma-se a isso, de acordo com Wittenbrink, Judd e Park (1997), ações legislativas de países ocidentais têm sido baseadas na coerção contra minorias.

A pessoa em conflito com a lei: preconceito e desigualdades de acesso

Segundo levantamento feito pelo Ministério da Justiça (Brasil, 2008), a quantidade de presos internados (presos provisórios, regime fechado, semiaberto, aberto, medida de segurança de internação e medida de segurança de tratamento ambulatorial) em sistema penitenciário em junho de 2008 totalizava 381.112 pessoas. Em relação ao gênero, 360.850 eram homens e 20.262 eram mulheres.

Neri (2004), em estudo baseado nos dados do IBGE (Instituto Brasileiro de Geografia e Estatística) do Censo Demográfico de 2000 sobre a população carioca, levantou um perfil de "presidiário preferencial" a partir de alguns fatores de risco associados a atividades criminosas. De acordo com o autor, o perfil do presidiário carioca seria de um homem, solteiro, natural da cidade, afrodescendente, com baixa escolaridade e sem religião. As características identificadas foram: 1) gênero - homens têm 27 vezes mais propensão a serem presidiários do que mulheres; 2) escolaridade - pessoas que estudaram por até seis anos têm cinco vezes mais propensão a serem presidiários em relação àqueles que apresentam mais de seis anos de estudo; 3 ) estado civil - solteiros são mais propensos a se envolverem em comportamentos de risco; 4) idade pessoas entre 18 e 35 anos têm três vezes mais chance de serem presas do que pessoas mais velhas; 5 ) religião - pessoas que não têm religião são $90 \%$ mais propensas a serem presas; 6) outras como migração, situação de desemprego e pobreza foram fatores menos importantes, mas não inexistentes.

Em trabalho sobre a identificação e caracterização do acesso diferencial ao sistema de justiça criminal brasileiro em relação à cor da pele, Adorno (1996), encontrou distinções em relação à menor vigilância policial sobre a população 
branca e maiores condições de acesso da mesma à justiça. Estas percepções foram apoiadas em dados que revelam menor incidência de prisões em flagrantes da população branca em comparação com a população negra, maior proporção de réus brancos respondendo seus processos em liberdade, menor dependência de defensoria pública, maior incidência de absolvição no desfecho do processo, entre outros. Do ponto de vista social, tanto réus brancos quanto negros eram oriundos de classes sociais desfavorecidas e com pouca oportunidade de escolarização. Os dados indicaram, portanto, um funcionamento jurídico baseado na discriminação racial e social de caráter impeditivo à garantia do princípio de igualdade dos cidadãos perante a lei. A teoria de hierarquia genética em defesa da superioridade da cor/etnia branca em relação à negra, o senso comum e a cultura política brasileira parecem ainda sustentar a idéia de existência de um perfil "potencial criminógeno" (Adorno, 1996). Pereira, Torres e Almeida (2003) explicitam que, além da consideração da influência genética, as teorias preconceituosas atuais são regidas, mais fortemente, pela crença numa hierarquia cultural.

A vigência de um poder excludente, que se dirige não somente contra o corpo do outro, mas também contra o existir deste no meio social, submete o indivíduo a um processo de coisificação que restringe possibilidades a partir do extermínio daquele que está à margem (Souza, 2004). Em meio ao jogo de poderes e manutenção ou obtenção de privilégios sociais, poderes paralelos ao Estado, como o narcotráfico e os grupos de extermínio, surgem enfraquecendo a aplicação pública da lei e da ordem e fortalecendo o sentimento de insegurança coletiva (Adorno, 2002; Souza et al., 1998). Especialmente entre a população jovem socialmente marginalizada, o caminho da ilegalidade relaciona-se fortemente com a conquista de status e falta de limite na tentativa de reconquista de cidadania (Fadino Marino, 2002).

Piovesan (2004) discute que, para haver uma maior contemplação das demandas de justiça social, o sistema universal precisa estar preparado para atender demandas além das políticas universalistas, focando na diversidade e vulnerabilidade de grupos, vítimas, em maior medida, do processo de exclusão.

Este trabalho tem por objetivo analisar a representação social da pessoa adulta que comete práticas ilícitas, a partir das respostas de estudantes universitários de características pessoais, econômicas e sociais desta população. Trabalhou-se com o referencial teórico da teoria das Representações Sociais, 
justificado pela elevada importância na vida social cotidiana do tema em questão. Acredita-se que o conhecimento a este respeito faz-se importante para o levantamento de expectativas sociais construídas nas relações cotidianas.

\section{MÉTODO}

A presente pesquisa teve caráter descritivo-exploratório (Contandriopoulos, Champagne, Potvin \& Boyle, 1997) focado na interpretação de estudantes sobre o adulto em conflito com a lei.

\section{Participantes}

Participaram deste estudo 55 estudantes universitários (42 do sexo feminino e 13 do sexo masculino) com idade média de 21,18 anos. Todas eram estudantes universitários dos cursos de Direito $(45,5 \%)$ e Psicologia $(54,5 \%)$ de uma universidade do Espírito Santo.

\section{Instrumentos}

Utilizaram-se instrumentos de caracterização do participante (sexo, idade, curso, período, etnia e renda familiar). Além disso, os participantes respondiam a questões sobre a personagem "João" após lerem uma história sobre a personagem com manipulação da variável bairro. Nesta história João tinha 40 anos, morador de bairro pobre ou rico do município de Vitória, ES. No ano anterior João havia perdido o emprego e não tinha conseguido outro, até então. Na história ele havia sido convidado por um(uma) amigo(a) a participar de uma atividade ilícita. Ao final da história, perguntava-se ao participante sobre: características do amigo de João (sexo, idade, local de moradia, escolaridade, etnia, estado civil, se trabalha, profissão); a prática ilícita que João foi convidado a cometer, se João aceitou a proposta, justificativa para João ter aceitado ou não a proposta e a pena merecida caso João aceitasse a proposta e fosse pego pela polícia.

De acordo com Spink (1993b) uma das formas mais comuns de obtenção de dados em Representações Sociais é a utilização do questionário. Como instrumento, o questionário seria uma forma verbal menos flexível de acessar as Representações do que a entrevista, contudo, adequada para amostras maiores. Para diminuir o impacto de uma possível inflexibilidade do questionário incluímos 
perguntas semi-abertas e abertas com intuito de possibilitar uma maior obtenção das percepções dos participantes.

\section{Coleta de dados}

Os dados foram coletados durante o horário de aula dos alunos, mediante permissão dos professores responsáveis pelas turmas no momento da coleta. Os participantes foram cientes dos objetivos da pesquisa e consentiram participação e utilização dos dados a partir de Termo de Consentimento e Esclarecimento de pesquisa.

\section{Análise de dados}

As questões abertas passaram por uma técnica da análise de conteúdo, a qual consiste em análise categorial em que o texto é dividido em unidades, em categorias semelhantes (Bardin, 1977/2004). O programa SPSS $®$ (Statistical Package for the Social Sciences) versão 16.0 foi utilizado para realizar as análises estatísticas. Os dados sobre o perfil do participante e as características do amigo de João foram tratados por estatística frequencial e descritiva. Utilizouse o teste Qui-quadrado ou o Teste de Fischer, quando necessário, a fim de examinar a associação entre o tipo de história (pobre $\mathrm{X}$ rico) ou o curso do participante e as categorias: local de moradia, escolaridade, etnia, estado civil, se trabalha, profissão, se aceitou a proposta do amigo, tipo de proposta feita pelo amigo, pena merecida por João e justificativa para ele ter aceito ou não a proposta. Finalmente, analisou-se as relações entre as características significativas do amigo de João (local de moradia, escolaridade) em uma análise de correspondência que é uma técnica de representação gráfica em projeção plana das relações multidimensionais das distâncias do Qui-quadrado entre as categorias das variáveis estudadas (Batista, Escuder \& Pereira, 2004).

\section{RESULTADOS}

\section{Caracterização dos participantes}

Participaram 55 estudantes do curso de Direito $(n=30)$ e Psicologia $(n=25)$. Vinte sete participantes responderam o questionário sobre o rapaz que morava em bairro pobre, enquanto 28 sobre o rapaz que morava em bairro rico. A maioria dos estudantes $(55.6 \%)$ declarou-se branca $(n=30)$ e $35.2 \%(n=19)$ pardos. Quanto à renda familiar, $47.3 \%(n=26)$ declararam ser maior do que $R \$$ 
$3761.00,27.3 \%(n=15)$ declararam ser entre $R \$ 1881.00$ e $R \$ 3760.00$ e $21.8 \%$ $(n=12)$ entre $R \$ 941.00$ a $R \$ 1880.00$.

\section{Características do amigo de João}

Os participantes atribuíram ao amigo de João uma idade média de 31.37 anos $(d p=8,54)$. Não houve diferenças estatisticamente significativas entre as categorias analisadas e o curso de quem respondeu o questionário (Direito ou Psicologia). Em conjunto, os participantes atribuíram com maior frequência ao amigo de João a cor/etnia parda $(n=28 ; 53.8 \%)$, sem união estável $(n=33$; $60 \%)$ e sem trabalho $(n=30 ; 54.5 \%)$. Dentre aqueles que apontaram que 0 amigo de João trabalhava $(n=25 ; 45.5 \%), 79.2 \%(n=19)$ destes acreditavam que ele tinha como profissão atividades lícitas como empresário, promotor de eventos, advogado, mecânico, etc. (as profissões apontadas foram as mesmas tanto para aquele que morava em bairro rico quanto para aquele que morava em bairro pobre), enquanto $20.8 \%(n=5)$ apontaram o tráfico ou outras atividades ilícitas como profissão.

A partir do teste do Qui-quadrado evidenciou-se diferenças estatisticamente significativas entre o tipo de história e: o local de moradia $\left(x^{2}(1)=30.081\right.$, $\mathrm{p}=0.0001)$ a escolaridade $\left(x^{2}(2)=20.306, \quad \mathrm{p}=0.0001\right)$ a cor/etnia $\left(X^{2}(2)=17.165, p=0.0001\right)$ e o estado civil $\left(X^{2}(1)=11.652, p=0.001\right)$ do amigo de João. As pessoas que responderam sobre a história do João que morava em bairro pobre com mais frequência que o amigo também provinha de bairro pobre $(n=23 ; 92 \%)$, tinha nível de escolaridade de ensino fundamental $(n=16$; $59.3 \%)$, cor/etnia parda $(n=19 ; 79.2 \%)$ e envolto em uniões estáveis $(n=17$; $63 \%$ ). Enquanto aqueles que responderam sobre a história do João que morava em bairro rico caracterizavam o amigo como alguém que também provinha de bairro rico $(n=20 ; 87 \%)$, com escolaridade de ensino superior $(n=14 ; 50 \%)$, cor/etnia branca $(n=18 ; 64.3 \%)$ e envolto em uniões sem estabilidade $(n=23$; $82.1 \%)$.

A análise de correspondência entre o tipo de história, o local de moradia e a escolaridade do amigo de João, evidenciou (Figura 1) duas dimensões para a projeção plana das categorias das variáveis que juntas representaram $86,1 \%$ das variações das distâncias do Qui-quadrado. Sugere-se, portanto, aproximação entre história do homem rico, moradia do amigo em bairro rico, cor/etnia branca, sem união estável e com Ensino Superior e história do homem pobre, moradia do 
amigo em bairro pobre, cor/etnia negra e/ou parda, escolaridade de ensino fundamental e com união estável.

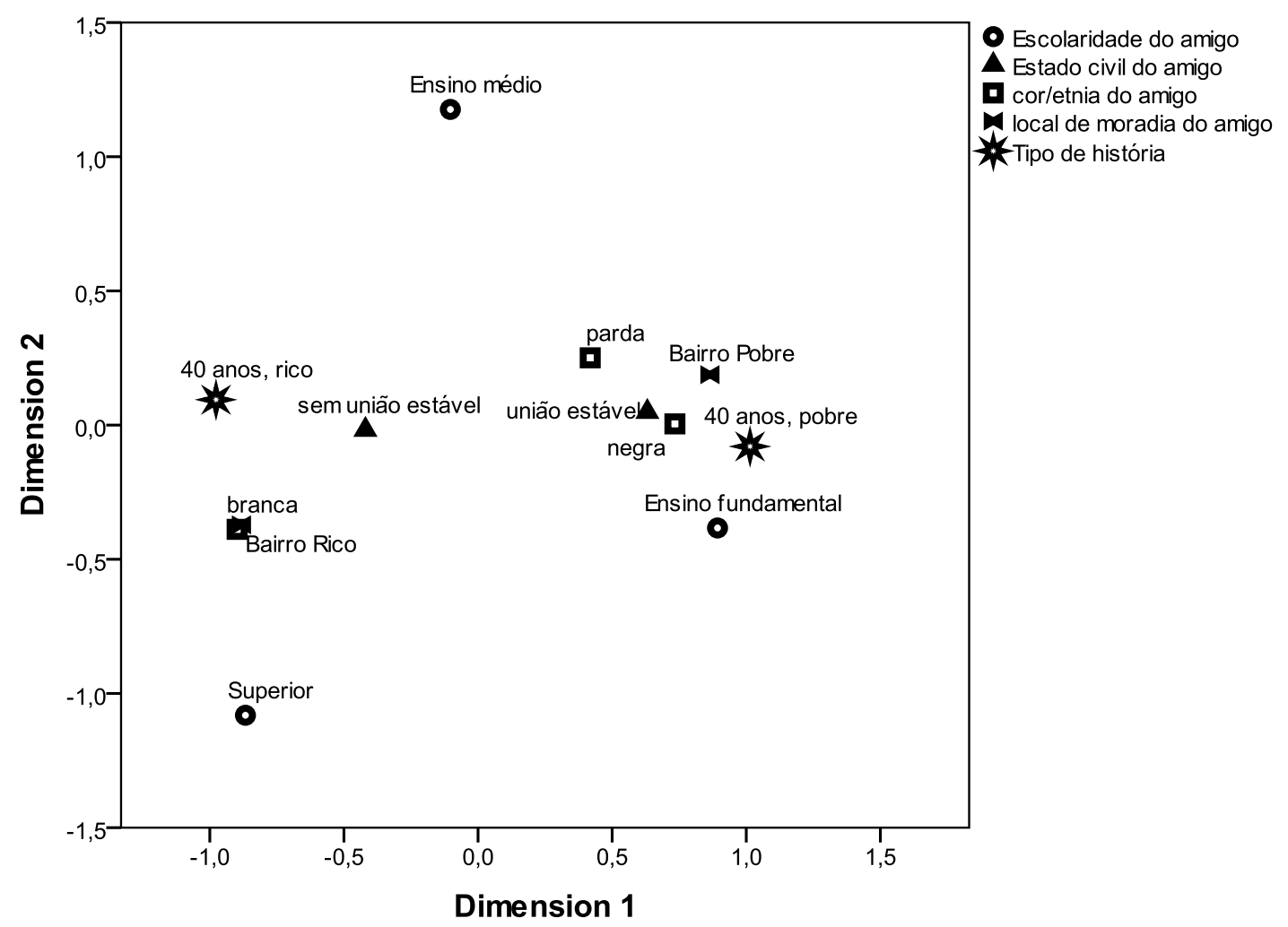

Figura 1.

Mapa das relações entre categorias de tipo de história que os participantes leram, local de moradia, cor/etnia, estado civil e escolaridade do amigo de João.

Aceitar ou não a proposta não dependeu do local de moradia de João: $50 \%$ $(n=13)$ das pessoas que responderam o questionário sobre o homem que morava em bairro pobre e $63 \%(n=17)$ das pessoas que responderam sobre 0 homem que morava em bairro rico acreditaram que ele aceitaria a proposta do amigo de se envolver em atividade ilícita. Os motivos para o engajamento na prática criminal foram categorizados em: "necessidade/falta de dinheiro", "falta de oportunidade" e "única alternativa", já os motivos para o não engajamento na prática criminal foram "características pessoais positivas" (responsável, maduro, trabalhador) e "medo da polícia/ser preso". A necessidade/falta de dinheiro foi apontada como o principal motivador (70.4\%) para a aceitação da proposta do amigo seja para garantir um recurso que nunca teve, seja para manter o status perdido ou ainda porque não aprendeu a respeitar regras sociais. Já as características pessoais positivas foram apontadas por $86.5 \%$ daqueles que 
justificaram o porquê João não aceitaria a proposta. Entre as possíveis práticas ilícitas propostas pelo amigo de João, destaca-se o tráfico com $73.6 \%$ das respostas.

Em relação à pena merecida, caso João aceitasse a proposta e fosse pego pela polícia, não houve diferenças estatisticamente significativas entre os cursos e nem entre os bairros: $66.7 \%$ dos estudantes de Direito apontaram "a pena prevista em lei", $29.6 \%$ a pena de prisão e 3.7\% as medidas socioeducativas. Entre os estudantes de Psicologia 60\% apontaram a prisão, 33.3\% a pena prevista na lei e $6.7 \%$ as medidas socioeducativas. Em relação ao bairro de moradia, $54.5 \%$ dos que responderam sobre o bairro rico previram a prisão como, $40.9 \%$ a punição prevista na lei e $4.5 \%$ medidas socioeducativas. Para aqueles que moravam em bairro pobre, $45.8 \%$ a penalidade prevista pela lei, $33.3 \%$ prisão e $20.8 \%$ medida socioeducativa.

\section{DISCUSSÃO}

Este estudo se baseou nas opiniões de estudantes universitários advindos, em sua maioria, de famílias com renda superior a seis salários mínimos e cor/etnia branca e segundo a revisão de literatura de Spink (1993a), as representações sociais estão intimamente relacionadas com o contexto, a época e as pessoas que sobre ela falam.

Focando-se um enunciado do instrumento proposto a partir da perspectiva socioeconômica, a questão a ser verificada foi se, levando-se em conta esta perspectiva, os entrevistados se limitariam à aceitação da situação de João como causadora do seu envolvimento criminal ou se, indo além, sua origem social pudesse afetar o julgamento. Encontramos que, para os estudantes, não somente pessoas que moram em periferias envolvem-se em atividades ilícitas, mas também aqueles que moram em bairros nobres, caracterizando dois perfis bastante relacionados às características pessoais das personagens principais: o primeiro de um sujeito morador de periferia, nível de escolaridade de ensino fundamental, cor/etnia parda e envolto em uniões estáveis e o segundo morador de bairro nobre com escolaridade de ensino superior, cor/etnia branca e envolto em uniões sem estabilidade. Estes resultados podem surpreender à primeira vista se considerarmos que comumente se aponta como causa da criminalidade as condições socioeconômicas de determinado grupo (Adorno, 1996; Macedo, Paim, Silva \& Costa, 2001; Zaluar, 2004; Adorno, 2002) e justifica-se, assim 
como no resultado desta pesquisa, o envolvimento criminal a partir das necessidades e limitações financeiras. Duas considerações hão de ser feitas para o maior entendimento destes perfis, uma em relação às causas atribuídas ao envolvimento criminal e outra relacionada a influencia exercida entre personagens.

Enquanto causas, os fatores socioeconômicos prevaleceram tanto entre os estudantes de Psicologia quanto os de Direito para justificar a aceitação de praticar atos ilícitos, uma vez que os entrevistados apontaram como causa predominante a necessidade/falta de dinheiro. Porém, ao indivíduo provindo de classe baixa a causa para o envolvimento criminal relaciona-se fortemente a recursos para a mínima sobrevivência, ou seja, ele não tem recursos financeiros e o crime é uma forma de ter, para o indivíduo provindo da classe alta sua necessidade está mais relacionada a manter o que já se tem, manter o status. Aqueles que opinaram pela recusa da personagem ao cometimento do ato infracional, o fizeram a partir da consideração de características pessoais positivas. Crer que situação de imersão social torna o homem cometedor de crime é desconsiderar fatores de proteção individuais, familiares e de apoio social presentes ou ausentes no ambiente (Pesce, Assis, Santos \& Oliveira, 2004) individual independente da situação econômica. Há de se levar em conta ainda que a ativação contextual da história proposta supõe que a personagem envolvida no crime precisa persuadir a personagem principal à participação na atividade proposta, precisando, portanto, ser "visível" e confiável, sendo assim, a personagem amiga não pode ser alguém excluída.

Em contrapartida, atributos apresentados para aquele que comete crimes, ou seja, o amigo de João, ficam marcados. No geral, o sujeito que comete crimes foi considerado de cor/etnia parda, sem união estável e sem emprego, categorizando a pessoa propensa ao cometimento de práticas ilícitas, confirmando os apontamentos de Adorno (1996) em pesquisa sobre características de réus e de Neri (2004) em levantamento sobre presos cariocas. Este discurso, formulado no meio acadêmico dos anos 70 e de inspiração marxista, ganhou o senso comum e é percebido nos mais diversos grupos (Zaluar, 2004). A partir da denúncia das consequências sociais da ordem econômica injusta coloca, tanto o criminoso quanto a vítima do crime, como vítimas comuns da má distribuição de renda e da falta de políticas públicas de inclusão. Há, no entanto, um risco inerente: o da naturalização e generalização 
do pobre como criminoso em potencial. Vítima das circunstâncias socioeconômicas, os mais desprovidos de recursos financeiros não poderia ser considerado moralmente responsável de forma plena pelo cometimento de crimes, afinal, não o foi dada condições, mas isso não impediria de reconhecê-lo como indivíduo perigoso e de justificar uma série de políticas e práticas de exclusão. Em suma a perspectiva socioeconômica do crime pode transformar-se, no senso comum, em preconceito contra pobres.

Diferenças e singularidades de cada um dos campos do saber a que pertencem os entrevistados (Direito e Psicologia) foram evidenciadas considerando a questão da punição sob perspectivas diferentes. Acredita-se que estudantes de Psicologia pertencem a um campo do saber no qual se apresenta problemas humanos e sociais a partir do prisma da solução ideal em termos políticos, humanos e sociais, já os estudantes de Direito são estimulados em seus estudos a encontrarem a norma adequada para a solução jurídica do conflito. Estas duas perspectivas levam os entrevistados de cada campo a formular a questão da justa retribuição de formas diferenciadas. Para o futuro psicólogo, o quão justa é ou não uma pena pode ser formulada em termos do resultado dessa pena sobre o comportamento do delinquente, portanto se a maioria dos estudantes de Psicologia apontou a prisão como pena adequada pode significar que acreditam que esta seja a forma adequada de correção da conduta de João. Já os futuros juristas reproduzem discurso comum do campo jurídico, e em especial no Direito Penal, no qual a justiça é confundida com a lei, considerando o resultado da aplicação dessa lei como um problema político, extralegal e, portanto, extrajurídico. É a máxima do ditado: dura lex, sed lex (A lei é dura, mas é a lei.). Em suma, futuros psicólogos avaliam o quão uma punição é justa por um critério consequencialista (pelo resultado da pena aplicada sobre o indivíduo), já futuros juristas a avaliam por um critério idealista no qual apenas o princípio de decisão (no caso, a lei penal) importa, independente dos resultados dessa aplicação.

Mesmo existindo um reconhecimento no campo da psicologia e no campo do direito de que as prisões brasileiras não oferecem as desejáveis e legais soluções para a reeducação e a possibilidade de retorno do indivíduo ao convívio social fora da prisão (Biscaia e Souza, 2005; Mameluque, 2006) e, apesar de existir uma política do Conselho Federal de Psicologia (Conselho Federal de Psicologia, 2008) em favor de medidas mais humanitárias de fazer valer a lei. A pena de 
prisão, que desde a II Guerra configura-se como espinha dorsal do sistema penal (Mameluque, 2006), é prioritariamente pensada como forma de punição. Focando-se no caráter preventivo e retributivo da sanção (Oliveira, 2006) a pena de prisão parece servir muito mais aos anseios das classes dominantes, as quais pertencem à amostra, a partir de uma visão vingativa, do que às necessidades reais de contribuição ao desenvolvimento pessoal e social da pessoa em conflito com a lei (Barreto, 2006).

Em contrapartida, soluções voltadas menos para a punição e a vingança social e mais focadas na reeducação e inserção social do apenado são amplamente difundidas e defendidas em ambos os círculos acadêmicos. De forma geral, essas alternativas à prisão são chamadas de medidas socioeducativas, ou seja, penas alternativas que são sanções criminais que não prevêem o aprisionamento e medidas alternativas que funcionam como instrumentos para impedir a aplicação da pena de prisão (Biscaia \& Souza, 2005). Os dois grupos, porém, coincidem no baixo apontamento desta ferramenta como pena merecida. Apesar de difundidas e defendidas em ambos os campos, as respostas tanto de futuros psicólogos quanto de futuros juristas apontam para uma descrença com relação às medidas socioeducativas. Se considerarmos ainda que a maior parte dos entrevistados afirmaram que João teria aceitado traficar drogas, que os estudantes de Direito sabem ser crime apenado pela lei com pena de reclusão, boa parte destes estudantes, ao aceitar "a pena prevista em lei" como a mais adequada, aceitaram também a prisão como a pena mais adequada em detrimento de medidas socioeducativas. De certa forma, considerando-se que mobilizações sociais dirigidas ao poder judiciário para a garantia de direitos daqueles que estão presos ou que já passaram pelo encarceramento e agora estão libertos são escassas, reafirma-se, que aquele que burlou regras sociais não merece a garantia de direitos, já que o mesmo não merece nem mesmo o convívio social e atua-se legitimando o tratamento para com aquele que transgrediu a regra, sem que o mesmo seja contemplado pelos direitos humanos (Caldeira, 1991; Souza et al, 1998).

\section{CONSIDERAÇÕES FINAIS}

A variável "bairro" mostrou-se relevante para a representação social da personagem João, apontando dois "perfis" bastante distintos conforme o bairro fosse pobre ou rico. De um lado, branco, sem união estável, com estudo superior 
ou médio, rico e morador de bairro rico. De outro, negro, com união estável, ensino fundamental ou médio, pobre e morador de bairro pobre. Estas diferenças sociais, apesar de refletirem o quadro de desigualdade social brasileiro, não foram relevantes para que se determinasse uma maior ou menor propensão da personagem João ao cometimento de crimes. Isto aponta para o fato de que, para os sujeitos entrevistados, desigualdade social não implica, por princípio, em desigualdade moral.

Por outro lado, as diferenças sociais impactaram o modo como as atitudes de cometer ou não um crime foram justificadas. Parece haver uma tolerância diversa ao envolvimento com o crime ligada a inserção social do indivíduo. Aquele que provém de classes desprovidas de recursos é concebido como vítima das circunstâncias econômicas quando se tenta explicar a delinquência, mas é tido como infenso a estas mesmas circunstâncias quando resiste a ela. A aceitação em delinquir não é considerada um ato de uma consciência livre, mas da situação socioeconômica. João não é moralmente responsável pela delinquência, mas mesmo assim deve pagar de forma punitiva ao cometê-la e quando resiste ao convite do crime, é um herói virtuoso. Já para aquele que tem recursos, não delinquir é a regra e aquele que o faz, comporta-se de maneira anti-social.

Dessa forma, a análise dos dados revela uma Representação Social que ampara antigas práticas punitivas contrárias aos direitos humanos e até mesmo a uma legislação vigente que não exclui a socioeducação da medida privativa de liberdade. Além disso, embora se tratando de uma amostra de estudantes de Direito e Psicologia, essa forma de pensar demonstra a dificuldade dos participantes em romper com o senso comum e o risco dos mesmos reforçarem a aplicação de tais formas de punição a uma parcela determinada da sociedade que se encontra inserida numa classe social desfavorecida.

\section{REFERÊNCIAS}

Abric, J. C. (1998). A abordagem estrutural das representações sociais. Em: Moreira, A.S.P, \& Oliveira, D.C (orgs). Estudos interdisciplinares de representação social. Goiânia: AB, 27-38

Adorno, S. (1996). Racismo, criminalidade violenta e Justiça penal: réus brancos e negros em perspectiva comparativa. Revista Estudos Históricos, 9(18). 
Adorno, S. (2002). Exclusão socioeconômica e violência urbana. Sociologias, Porto Alegre, 4(8), 84-135.

Alexandre, M. (2004). Representação social: uma genealogia do conceito. Comum, 10(23), 122-138.

Bellodi, P. L. (2004). The general practitioner and the surgeon: stereotypes and medical specialties. Revista do Hospital das Clínicas. Faculdade de Medicina São Paulo. 59(1),15-24.

Barreto, M. L. (2006). Depois das grades: um reflexo da cultura prisional em indivíduos libertos. Psicologia: ciência e profissão, Brasília: Conselho Federal de Psicologia, 26(4), 582-593.

Batista, L. E., Escuder, M. M. L. \& Pereira, J. C. R. (2004). A cor da morte: causas de óbito segundo características de raça no Estado de São Paulo, 1999 a 2001. Revista de saúde Pública, 38(5), 630-636.

Biscaia, L. S. \& Souza, M. A. (2005). Penas alternativas: dimensões sócioeducativas. Publicatio, Ponta Grossa, 1(1), 127-135.

BRASIL. Constituição da República Federativa do Brasil. Congresso Nacional, Brasília, 1988.

BRASIL. Relatórios Estatísticos - Analíticos do sistema prisional de cada Estado da Federação. Ministério da Justiça. Brasil, junho/2008. disponível em http://www.mj.gov.br/data/Pages/MJD574E9CEITEMIDC37B2AE94C684006 8B1624D28407509CPTBRIE.htm - último acesso em 15 de março de 2012.

Brito, H. B. \& Catrib, A. M. F. (2004). Social representation and subjectivity of becoming mentally ill. Estudos de psicologia (Natal), 9(2), 285-296.

Caldeira, T. P. R. (1991). "Direitos humanos ou privilégio de bandidos"? Desventuras da democratização brasileira, Novos Estudos, 31,162-174.

Conselho Federal de Psicologia. (2008). Falando Sério sobre prisões, prevenção e segurança pública. Proposta do Conselho Federal de Psicologia para o enfrentamento da crise do sistema prisional. 42p.

Contandriopoulos, A. P., Champagne, F., Potvin, L. \& Boyle, P. (1997). Saber preparar uma pesquisa. São Paulo - Rio de Janeiro: Editora Hucitec Abrasco.

Fadino Marino, J. M. (2002). Análise comparativa dos efeitos da base socioeconômica, dos tipos de crime e das condições de prisão na reincidência criminal. Sociologias, Porto Alegre, 8. 
Macedo, A. C., Paim, J. S., Silva, L. M. V. \& Costa, M. C. N. (2001) Violência e desigualdade social: mortalidade por homicídios e condições de vida em Salvador, Brasil. Revista de Saúde Pública, 35(6), 515-522.

Mameluque, M. G. C. (2006). A subjetividade do encarcerado, um desafio para a psicologia. Psicologia: ciência e profissão, Brasília: Conselho Federal de Psicologia, 26(4), 620-631.

Oliveira, V. (2006). Pena e vingança. A pena de prisão nos crimes contra a Administração. Jus Navigandi, Teresina, 10(924).

Pereira, C., Torres, A. R. R., \& Almeida, S. T. (2003). Um Estudo do Preconceito na Perspectiva das Representações Sociais: Análise da Influência de um Discurso Justificador da Discriminação no Preconceito Racial. Psicologia: Reflexão e Crítica, 16(1), 95-107.

Pesce, R. P., Assis, S. G., Santos, N. \& Oliveira, R. V. C. (2004). Risco e proteção: Em busca de um equilíbrio promotor de resiliência. Psicologia: Teoria e Pesquisa, 20(2), 135-143.

Piovesan, P. (2004). Direitos sociais, econômicos e culturais e direitos civis e políticos. Revista Internacional de Direitos Humanos, 1(1), 20-47.

Queiroz, R. S. \& Otta, E. (2000). A beleza em foco: Condicionantes culturais e psicobiológicos na definição da estética corporal. In R.S. Queiroz (org). 0 corpo do brasileiro: Estudos de estética e beleza. São Paulo, Senac, 13-66.

Neri, M. C. (2004). Retratos do Cárcere. Conjuntura Econômica, Rio de Janeiro, $20,70-71$.

Souza, L., Rosa, A. L. I., Effgen, H. K. K., Paiva, A. V., Toniato, M. \& Alvim, S. F. (1998). Direitos humanos e representação de justiça. Psicologia: Reflexão e Crítica, 11(3), 497-510.

Souza, L. (2004). Processos de categorização e identidade: solidariedade, exclusão e violência. In Souza, L., \& Trindade Z. A. (orgs). Violência e exclusão: Convivendo com paradoxos. São Paulo: Casa do Psicólogo, 57-74.

Spink, M. J. P. (1993a) O conceito de representação social na abordagem psicossocial. Caderno de Saúde Pública, Rio de Janeiro, 9(3).

Spink, M. J. P. (1993b). O estudo empírico das Representações Sociais. In: Spink, M. J. P. (Org.) O conhecimento no cotidiano - As representações sociais na perspectiva da psicologia social. São Paulo, Brasiliense, $1^{\text {aed. }}$ 
Wittenbrink, B., Judd, C. M. \& Park, B. (1997). Evidence for racial prejudice at the implicit level and its relationship with questionnaire measures. Journal of Personality and Social Psychology, 72, 262-274.

Zaluar, A. (2004). Integração perversa: Pobreza e tráfico de drogas. Rio de Janeiro: FGV.

Contato: biacarnielli@usp.br, danybartnasc@yahoo.com.br, edineter@gmail.com, julio@pompeu.org

Recebido em: 29/03/2012

Revisado em: 20/05/2012

Aceito em: 19/06/2012 